FL-treated B cells on SGs by co-culture of these circulating B cells with human SG (HSG) epithelial cell line cells.

Results (1) There were more serum FL in SS patients that in HCs $(135.8 \pm 5.5$ vs $64.4 \pm 4.5 \mathrm{pg} / \mathrm{ml}, \mathrm{p}<0.001)$, their levels correlated with the clinical activity of the disease and with the proportions of $\mathrm{Bm} 2 / \mathrm{Bm}^{\prime}$ in the $\mathrm{PB}(\mathrm{r}=50, \mathrm{p}<0.001)$. (2) Furthermore, Flt3 was selectively expressed in these circulating $B$ cell subsets. With regard to the SGs, B cells expressed Flt3, while epithelial cells produced FL. (3) Finally, co-cultures revealed that FL potentiated the $B$ cell receptor-induced proliferation of $B$ lymphocytes, and the HSG-mediated survival of B cells was abrogated by anti-FL and/or anti-Flt3 antibodies.

Conclusion The pSS patients increase their serum levels of $\mathrm{FL}$, relative to the excess of $\mathrm{Bm} 2 / \mathrm{Bm}^{\prime}$ in their $\mathrm{PB}$. By supporting the proliferation of $B$ cells, FL favours the development of B cell lymphoma in SS.

\title{
A35 SJÖGREN'S SYNDROME (SS): ARE INCREASED SERUM LEVELS OF CYTOKINE FMS-LIKE TYROSINE KINASE 3 LIGAND (FLT3L) INDICATIVE OF LYMPHOMA?
}

G J Tobón, V Devauchelle, P Youinou, J-0 Pers EA 2216 'Immunologie et Pathologie' and IFR 148 ScInBioS, Université de Brest, and Université Européenne de Bretagne, Brest, France

\subsection{6/ard.2010.129585i}

Background Flt3L, which is involved in the ontogenesis of $B$ cells (particularly in their malignant proliferation in pSS) might contribute to the absolute excess of activated Bm2/germinal centre funder Bm2' B lymphocytes which characterises the peripheral blood (PB) pattern of these patients.

Objectives Our aims were threefold: (1) Compare the serum levels of FL of 64 Sjögren's syndrome (SS) patients with those of 20 healthy controls (HCs). (2) Quantify B cell expression of this ligand and its receptor Flt3 in the PB and the salivary glands (SGs) of patients. (3) And evaluate the effect of 